\title{
What's new in the mechanisms of enzyme regulation?
}

\section{Edwin G. Krebs}

Protein Phosphorylation in Regulation: Recently Discovered Systems of Enzyme Regulation by Reversible Phosphorylation. Vol. 1 of Molecular Aspects of Cellular Regulation. Edited by P. Cohen. Pp.273. ISBN 0-444-80226-6. (Elsevier/ North-Holland Biomedical: 1980.) \$63.50, Dfl. 130.

As the title of this first volume in a series on cellular regulation suggests, the emphasis is on new systems that for the most part have not been reviewed extensively heretofore. The editor of the series, Philip Cohen, who is one of the world's foremost authorities on protein phosphorylation, provides an introductory chapter that gives an excellent summary of the well-established role of this process in the regulation of glycogen metabolism. His succinct account will provide readers with a broad outline of the history and evolution of the general principles of protein phosphorylation, but at the same time will not burden them with an enormous load of information that is available elsewhere. A more exhaustive treatment of glycogen metabolism in this book would have detracted from the reviews that follow. These include chapters by different authors on pyruvate kinase, acetyl CoA carboxylase, hydroxymethylglutaryl $\mathrm{CoA}$ reductase, steroidogenesis, triacylglycerol synthesis, muscle contraction, protein synthesis, the phosphorylation of ribosomal proteins and the phosphorylation of histone $\mathrm{H} 1$. Parenthetically, it should be noted that the word "enzymes" is used in a very loose sense in this volume, in that the topics covered include the phosphorylation of proteins ordinarily not thought of as enzymes.

The individual contributions, which, with one exception, are clear and well written, follow a general theme developed in the introductory chapter. Brief descriptions of the more classical enzymology of a given system, including non-covalent regulation, are followed by the more recent work concerned with phosphorylation-dephosphorylation. The latter, which constitutes the principal thrust of each article, is generally handled by progressing from in vitro phosphorylation to the more difficult in vivo situations. Most of the authors make an effort to apply criteria of physiological relevance to the phosphorylation phenomena that have been observed. This aspect is especially well handled in sections on the regulation of pyruvate kinase, the control of protein synthesis and the modification of histone $\mathrm{H}$. A final chapter in the book, again written by Cohen, highlights common features of the various phosphorylation systems and forecasts future directions that will be taken by workers in this field; in addition, he introduces an interesting hypothesis concerning the mechanism of action of insulin in the regulation of protein phosphorylation.

The book can be recommended for readers who desire timely, concise reviews of work on various aspects of metabolic regulation controlled by protein kinases and phosphoprotein phosphatases. It is designed more for the non-specialist than for the specialist, but anyone reading the volume will profit from the experience, particularly if he reads it in its entirety.

Edwin G. Krebs is a Senior Investigator at the Howard Hughes Medical Institute and Chairman of the Department of Pharmacology, University of Washington, Seattle.

\section{Newtonian style and scientific revolution}

\section{Richard S. Westfall}

The Newtonian Revolution, with Illustrations of the Transformation of Scientific Ideas. By I.B. Cohen. Pp.414. ISBN 0-521-22964-2. (Cambridge University Press: 1981.) $£ 18, \$ 37.50$.

TwENTY-five years ago, Professor Cohen's influential Franklin and Newton (American Philosophical Society, 1956) established him as the foremost student of Newtonian natural philosophy. Over the intervening years a constant stream of publications has at once expanded our understanding of Newton and the scientific revolution and maintained Cohen's position. To that stream he now adds another major volume, The Newtonian Revolution, the revised text of the Wiles Lectures delivered at the Queen's University of Belfast. As the two-part title suggests, the book divides into two major sections, one on the Newtonian revolution in science, the other on the doctrine of transformations as an interpretive explanation of the development of scientific ideas. Though the book contains several lengthy asides which are connected only tenuously to the central argument, the two sections maintain a fundamental unity by focusing on the same developments in Newtonian science. In Cohen's view - a view that most historians of science would enthusiastically endorse - the elaboration of the Principia was the single most important step forward in the course of modern science. The appearance of Professor Cohen's detailed analysis of it constitutes a major event in the historiography of science.

While the title of Part I recalls Thomas Kuhn's Structure of Scientific Revolutions, it is Part II, Transformations of Scientific Ideas, which speaks directly to the issues Kuhn raised. Where Kuhn argued for discontinuities in the growth of science, revolutions characterized by sudden switches in the perception of nature, Cohen stresses continuity in which every revolution is achieved by the transformation of received concepts. He is presently at work on a general exposition of his theory of scientific growth. In the present volume he illustrates it by examining the same events that are central to his understanding of the Newtonian revolution. For the latter he develops the important concept of the Newtonian style by which he seeks both to identify the essence of Newton's contribution and to characterize the nature of modern science. Central to the Newtonian style is the use of mathematical constructs which successive modifications make ever more adequate to the full complexity of physical reality. Equally important is the postponement of enquiry into causes until maximum agreement between the construct and the world of experience has been at tained. The idea of the Newtonian style enables Cohen to distinguish Newton's approach from that of other quantifiers and geometrizers in seventeenth century science. No one insisted more on the role of geometry in natural philosophy than Kepler, but, as Cohen shows, Kepler started with causal hypotheses and arrived at mathematical constructs, whereas the Newtonian style proceeded in the opposite order. The primacy of causal hypotheses likewise separated Newton from his continental critics, who were not inconsiderable mathematicians. As I indicated, the concept of a Newtonian style in science, which Cohen argues persuasively was a more important ingredient in his enduring influence than the specific content of the Principia, strikes me as a major contribution to our growing understanding of the scientific revolution.

I feel bound to add that, in my opinion, there are problems attached to this exposition of the concept. Professor Cohen has confounded what philosophers call the context of discovery with the context of justification and has insisted, almos! perversely, in using a concept adapted to the context of justification to expound Newton's process of discovery. Few scientists have been less autobiographical in their publications than Newton. He was on the one hand an extremely introverted man who was always concerned to keep his 